RASP R Recarachon anging and Social Policy

Instructions for authors, subscriptions and further details:

http://rasp.hipatiapress.com

\title{
Desarticulando las Fronteras del Erotismo en la Vejez
}

Ricardo lacub, Patricia Hidalgo López, Martín Osvaldo Winzeler, Valeria Bourlot, Mariana Laura Gil de Muro, Mariana Paz, Mónica Liliana Bellas, Luciana Machluk, Rocío Vazquez Jofré y Patricia Boggiano

Universidad Nacional de Buenos Aires. Argentina

Date of publication: January $30^{\text {th }}, 2020$

Edition period: January 2020- June 2020

To cite this article: lacub, R., Hidalgo, P., Winzeler, M. Bourlot, V., Gil de Muro, M.L., Paz, M., Bella, M. L. Machluk, L., Vazquez, R. y Boggiano, P. (2020). Desarticulando las fronteras del erotismo en la vejez. Research on Ageing and Social Policy, 8(1), 1-24. doi: 10.4471/rasp.2020.4616

To link this article: http://dx.doi.org/10.447/rasp.2020.4616

\section{PLEASE SCROLL DOWN FOR ARTICLE}

The terms and conditions of use are related to the Open Journal System and to Creative Commons Attribution License (CCAL). 


\section{Disarticulating the Frontiers of Eroticism in Old Age}

Ricardo Iacub

Patricia Hidalgo López

Martín Osvaldo Winzele

Valeria Bourlot

Mariana Laura Gil de Muro

Universidad Nacional de Buenos Aires
Mariana Paz

Mónica Liliana Bellas

Luciana Machluk,

Rocío Vazquez Jofré

Patricia Boggiano

(Received: 30 August 2019; Accepted: 19 November 2019; Published: 30 January 2020)

\section{Abstract}

The aim of this article is to understand the diversity of narratives about the eroticism of older adults and present the alternatives they find in their ways of enjoying and wishing and the way in which they build these stories. A qualitative investigation is presented where 40 semi-structured interviews were conducted with 28 women between 65 and 86 years old and 12 were men between 70 and 90 years old. Three central categories were delimited: the characteristics of eroticism, changes in aging and compensation strategies. There were a variety of forms of enjoyment and desire that can be articulated without constituting pre-established models of integration; losses in physical functioning and lack of positive representations at the social level, and possibilities of compensation, replacements, alternative routes and the discovery of resources

Keywords: old age, eroticism, sexuality 


\section{Desarticulando las Fronteras del Erotismo en la Vejez}

Ricardo Iacub

Patricia Hidalgo López

Martín Osvaldo Winzeler

Valeria Bourlot

Mariana Laura Gil de Muro

Universidad Nacional de Buenos Aires
Mariana Paz

Mónica Liliana Bellas

Luciana Machluk,

Rocío Vazquez Jofré

Patricia Boggiano

(Recibido: 30 agosto 2019; Aceptado: 19 noviembre 2019; Publicado: 30 enero 2020)

\section{Resumen}

El objetivo de este artículo es comprender la diversidad de narrativas sobre el erotismo de las personas adultas mayores y presentar las alternativas que encuentran en sus formas de gozar y desear y el modo en que construyen esos relatos. Se presenta una investigación cualitativa en donde se tomaron 40 entrevistas semi estructuradas a 28 mujeres de entre 65 y 86 años y a 12 fueron hombres de entre 70 y 90 años. Se delimitaron tres categorías centrales: las características del erotismo, los cambios en el envejecimiento y las estrategias de compensación. Se presentaron una diversidad de formas de goce y deseo que pueden articularse sin constituir modelos preestablecidos de integración; pérdidas en el funcionamiento físico y carencias de representaciones positivas a nivel social, y posibilidades de compensaciones, reemplazos, vías alternativas y el descubrimiento de recursos.

Palabras clave: vejez, erotismo, sexualidad 


\section{Iacub et al. - Desarticulando las fronteras del erotismo}

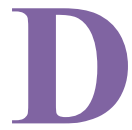

esarticular las fronteras teóricas que constituyen los espacios preconcebidos del deseo y el goce erótico, particularmente en la vejez, resulta un esfuerzo necesario a la hora de entender los constantes flujos de innovación que se promueven tanto a nivel individual como colectivo, o en la interacción entre ambos.

El erotismo es un territorio tan vasto como complejo que requiere ser diseccionado a partir de lecturas disímiles que permitan conocer la dialéctica entre lo inicial y lo final, entre sus valores hegemónicos y marginales que remiten a variantes de género y generación, o en las múltiples y singulares maneras en que se acuñan sus significados.

Las metáforas del deseo y el goce erótico alojan recuerdos, espacios del presente y posibilidades a futuro. Aunque, también, el lenguaje es capaz de proyectar el pasado en el futuro y hacer de esa improbable anticipación un relato deseable y gozable. Desarticular implica recorrer, conocer y proyectar horizontes de significados que habiliten profundizar sus tramas más sutiles. Es allí donde las adversidades emergentes en la capacidad para el deseo y los goces en la vejez generan formas de resiliencia que dan lugar a otras producciones de disfrute.

Para conseguir este objetivo se buscará deconstruir (Derrida, 1988) las categorías teóricas que organizan sentidos, afectos o prácticas y reencontrar los términos, las imágenes, los objetos que invoquen e incluyan al deseo y el goce del erotismo. Se presentarán resultados de una investigación que muestra la emergencia y dispersión, para finalmente enhebrar los hilos que articulen un mapa alternativo de relatos.

\section{El Análisis del Erotismo}

Construir un relato sobre los modos en que se describe el deseo y el goce del erotismo en la vejez requiere analizar las palabras y los significados atribuidos que mejor se adecuen a dicho propósito. Por ello, resulta necesario el análisis que muestre la conformación de un concepto a partir de procesos históricos y acumulaciones narrativas (Derrida, 1988).

Desde una perspectiva posgerontológica (Iacub, 2002, 2003, 2013) el objetivo es reflexionar sobre la incidencia que se ejerce sobre la erótica y el erotismo en la vejez, presentando las variantes situacionales y socio 
históricas en los que emergieron, así como criticando, de esta manera, las "naturalizaciones" y posibilitando transformaciones en las políticas que estatuyen goces o represiones.

Los términos sexo y sexualidad aparecen como referentes de múltiples sentidos, lo que genera un vocablo incluyente al tiempo que excesivamente polisémico.

Una de sus acepciones más claras indica las marcas biológicas que establecen condiciones de disfrute, las que fueron consideradas como zonas erógenas (Freud, 1905). De ello se desprende un impulso al deseo y una capacidad efectiva de goce que toma bases en la biología y se organizan en lo psicológico. De este modo, los recursos biológicos relativos a la sexualidad se incluyen a nivel del psiquismo humano dando lugar al "impulso sexual" y a la "erogenización corporal". Ambos términos, que aluden al concepto de pulsión (Freud, 1915) delimitan la fuerza y la capacidad psicofísica para el deseo y el goce erótico, que serán utilizadas en el contexto de este escrito.

La palabra sexualidad se ha convertido en uno de los referentes más habituales para referir al conjunto de criterios que socialmente se abordan en relación a esta temática. De hecho, para la OMS (2006), la sexualidad abarca al sexo, las identidades y los papeles de género, el erotismo, el placer, la intimidad, la reproducción y la orientación sexual. Se vivencia y expresa a través de pensamientos, fantasías, deseos, creencias, actitudes, valores, conductas, prácticas, papeles y relaciones interpersonales, generando una multiplicidad de criterios que se validan sólo como términos referenciales debido a su falta de precisión.

Foucault (1995) realizó una crítica a la noción clásica de sexualidad basándose en el origen de la palabra ya que consideraba que el siglo XIX construyó una ciencia del sexo, lo que determinó que se la conciba desde su alto potencial patológico y que se generen intervenciones terapéuticas o de normalización. Cuestión que en la actualidad mantendría ciertos niveles de vigencia y que se verifica en la denominada educación "sexual” la cual sigue siendo un espacio de prevención de patologías o de embarazos y no de formación de los goces para acceder al placer relativo al sexo. Esta mirada patologizante aparece con particular fuerza en los grupos que se los considera marginales, como los viejos. 


\section{Iacub et al. - Desarticulando las fronteras del erotismo}

El psicoanálisis delimitó los campos del deseo y el goce sexual dividiendo aquellos específicamente genitales de los sexuales. Estos últimos alojaban una importante variedad de experiencias que no se referían directa o indirectamente a lo genital. Cuestión que cobró importancia histórica en la medida que facilitó otra comprensión de la temática, aun cuando la cercanía conceptual a la perversión no quedó uniformemente saldada en las diversas líneas de este marco teórico (Iacub, 2006).

A diferencia de las significaciones generadas sobre la sexualidad, el erotismo descubre un campo diferencial que expresa su mayor correlación con el placer. Foucault (1995) entendía el arte erótico como la búsqueda o realización de un tipo de disfrute relativo a lo sexual aunque no referido a criterios morales o utilitarios propios de los criterios de una época, sino a una relación personal. Más allá de lo cuestionable de esta definición, en tanto la relación entre los valores preestablecidos y "lo personal", se encuentran en una continua interacción, es importante señalar que el erotismo focaliza las búsquedas y realización de goces. El considerarlo un arte permite concebirlo como un ejercicio creativo, no sujeto a reglas rígidas.

De esta manera el erotismo emerge como un concepto que permite delimitar el deseo y el goce de una manera más amplia y con criterios de estilo propios de un sujeto o autor que se encuentra implicado en contextos diversos, redimensionando de esta manera las nociones de impulso sexual y erogenización corporal. En esta línea, Featherstone (1998) lo define como la infinita variedad de formas basadas en una constante invención, elaboración, domesticación y regulación del impulso sexual, a lo que se añadirían los criterios de época.

Para Octavio Paz (2004) el erotismo es la sexualidad transfigurada por la imaginación humana, la que se constituye como la metáfora de la sexualidad animal: "está más allá de la realidad que la origina", y se presenta como "algo nuevo y distinto de los términos que la componen" (p. 10). Esta metáfora permite pensar en la capacidad simbólica y constructiva para redimensionar los mecanismos de la sexualidad, conformando espacios que aluden a la misma, sin que requiera necesariamente de relaciones genitales $u$ otras zonas erógenas. En este sentido, el erotismo se construye sobre modos de representar las formas sucedáneas, símiles o alusivas de lo sexual, capaces de conjugar imágenes, afectos y sensaciones. Dichos constructos 
son considerables como narraciones que articulan relatos y sensaciones de muy diverso orden, los cuales promueven, inducen y activan el goce sensual en el sujeto y en el objeto.

De esta manera, el erotismo podría ser considerable como una multiplicidad de goces sensoriales y mentales, que se activan ante estímulos variados y generan respuestas físicas y hormonales asociadas a lo que Masters y Johnson (1966) denominaron como respuesta sexual humana. Estos goces pueden articularse sin que por ello se constituyan en modelos preestablecidos de integración, ni se organicen según recorridos fijos. De esta forma, comprender los modos de enunciación del erotismo en la realización del deseo, implica la inclusión de referentes biológicos, los modos de los relatos de autor y los parámetros eróticos de una época.

Entre los modos de componer su organización aparece por un lado el deseo, como anhelo de realización de un placer en un tiempo diferido, lo que se vuelve particularmente evidente en las fantasías y, por el otro, está el goce como realización efectiva. Sin duda, la diferencia entre una y otra resulta más clara a nivel conceptual ya que en la experiencia ambas se solapan, habiendo en el desear un goce y en el goce una expectativa de deseo.

El erotismo requiere de la articulación entre sensaciones físicas y relatos organizadores. Estos últimos, entendidos como espacios con actores caracterizados y con guiones relativamente flexibles. Dichos relatos responden a criterios personales y culturales que indican valores estéticos, posibilidades de género, edad y orientación sexual.

Los relatos del erotismo se originan tanto en las relaciones objetales tempranas, dando modelos de mayor permanencia, como en las contingencias personales que emergen ante cambios vitales, de tipo psicológico, físico o social. La narrativización conjuga, en cada encuentro, los relatos sociales disponibles sobre el deseo, los modos singulares de los goces, la imbricación del impulso sexual y la erogenización corporal.

Estos criterios toman un valor particular en el envejecimiento donde pueden disminuir los niveles del impulso, de erogenización de ciertas zonas y la posibilidad de acoplamiento, y en el que una cultura conspira negativamente contra esta posibilidad.

Por esto es importante considerar otras modalidades de producción de saberes que den lugar a la "producción continua de diferencia" (Sandberg, 


\section{Iacub et al. - Desarticulando las fronteras del erotismo}

2011, p. 19) en tanto permitan salir de la lógica de la capacidad o la incapacidad, ya sea a nivel genital, lo reproductivo, o de los códigos del atractivo estético imperante.

$\mathrm{Si}$ en el erotismo priman los modos singulares, la erótica describe condiciones socioculturales desde donde se narran los goces del erotismo y se le imprime un relato de época que permite escenificar las formas del deseo y del goce, el cortejo, las fantasías, los objetos deseables entre otros, dotándolos de reglas o parámetros que los organizan. Lo que Bauman (1999) definió como el procesamiento cultural del sexo.

\section{Investigaciones sobre el Erotismo en la Vejez}

En la vejez existen diversos factores que pueden producir cambios en las formas de goce: el funcionamiento físico que puede alterar el deseo o la competencia genital; los cambios o la carencia de pareja (Lindau et al., 2007); en los valores estéticos que desestiman los cuerpos de los viejos; las narrativas valores culturales que niegan los goces en esta etapa, y la falta de educación sexual, entre otros.

Los cambios en el funcionamiento físico inciden en la mitad de las personas mayores sexualmente activas, manifestándose en algún problema sexual (Lindau et al., 2007). En los varones son más frecuentes las dificultades de erección, y en la mujer la disminución del deseo sexual, problemas de lubricación vaginal y la no consecución del orgasmo. Smith, Mulhall, Deveci, Monaghan y Reid (2007) encontraron resultados similares al mostrar que la falta de interés en las mujeres y la disfunción eréctil en los varones eran los motivos principales de la menor actividad sexual.

Entre los factores culturales que inciden negativamente se encuentran los valores de género. Para las mujeres la falta de un fin reproductivo, la viudez y la menor sensación de ser deseables y valiosas se convierten en los factores más relevantes para el abandono de ciertas prácticas eróticas. Así como el cuerpo, la imagen de la mujer vieja, es connotada por la desestima erótica. Lo que devela una demanda cultural que promueve que las mujeres vean sus cuerpos como objeto de evaluación estética (Calsanti y Slevin, 2001) y en fuerte comparación con otras mujeres (Iacub, 2005). Sin embargo, es interesante destacar las diferencias en las clases sociales, ya que en las 
clases medias y altas el proyecto del cuerpo es más estético, mientras que en las clases más bajas el cuerpo aparece más instrumentalizado (Calasanti y Slevin, 2001).

En las sociedades occidentales, la demanda relativa a la capacidad sexual resulta más exigente para los hombres que para las mujeres, dado que la falta de rendimiento es vista como falta de virilidad. Siever (1994) agregaba que los hombres parecen más interesados en su fuerza, su capacidad física y su rendimiento, en competencia con otros hombres, y donde la falta de rendimiento sexual puede amenazar su autoimagen (Huick, 1977). Por lo contrario, Bortz, Wallace y Willey (1999) mostraron que un número sustancial de varones viejos continuaba activo sexualmente cuando tenían actitudes positivas hacia la sexualidad y cuando no había un aislamiento social ni problemas de salud.

Los cambios producidos en la cultura sexual contemporánea pudieron revisar dichos discursos, aun cuando la lógica biomédica de una sexualidad básicamente genital prevalece. Sandberg (2011) cuestionó la fijeza de las morfologías sexuales fálicas, para indagar los borrosos confines del erotismo. Lo que implicó criticar los ajustados límites de una moral burguesa que reprimió todo aquello que desbordara el rendimiento del sexo reproductivo. En esta línea Fileborn et al. (2015) definieron, en un estudio sobre mujeres adultas mayores, a la subjetividad sexual como la comprensión del sexo y del deseo sexual subjetivo e individual, en tanto se promueven cambios de jerarquías, que den lugar a un entendimiento más amplio e inclusivo. Asimismo Starr y Weiner (1981) sugirieron que ante la aceptación de la variabilidad y el alcance de la expresión sexual resulta importante la educación acerca de los cambios que se producen en el funcionamiento sexual durante el envejecimiento. Sus hallazgos indican que las personas mayores pueden manifestar su erotismo en formas más difusas, y estar menos orientadas por metas. La experiencia se convierte en una instancia que puede ser menos definible cuantitativamente y más en términos cualitativos; es decir, donde el peso recaiga sobre el significado y la calidad de sus relaciones. López Sánchez (2005) incluye en los códigos de lo erótico el sentirse queridos, reconocidos y valorados, el disponer de relaciones que brinden apoyo, así como la necesidad de caricias mutuas, besar y ser besado, abrazarse, explorar y ser explorado, excitarse uno al otro, disfrutar del placer 


\section{Iacub et al. - Desarticulando las fronteras del erotismo}

sexual y fundamentalmente de la intimidad tanto corporal como afectiva. Bellato Gil (2016) estudia la experiencia erótica en personas mayores a través de la simbolización y de los significados atribuidos a los objetos personales, tales como canciones, poemas, recuerdos que conforman una memoria erótica que les permite recrearse, actualizarse como personas, legitimarse frente a los demás, y reconocer y revalorar sus capacidades de deseo y goce para relacionarse con otras personas y consigo mismos. Por último Iacub (2015) define la "sabiduría del erotismo en la vejez" como un recurso cognitivo, reflexivo y emocional para tratar las variables circunstancias biológicas y culturales sobre el deseo y el goce. Lo que posibilita la formación de goces supletorios que fortalecen la integridad personal.

\section{Objetivos}

El objetivo general de esta investigación ha sido indagar sobre los cambios que se producen en el erotismo en las personas mayores. En cuanto a los objetivos específicos, destacan: (1) Conocer las diversas modalidades en que las personas mayores describen su erotismo. (2) Describir los cambios se producen en el erotismo en la personas mayores. (3) Distinguir las estrategias que utilizan las personas para mantener el erotismo.

\section{Metodología}

Para la presente investigación exploratoria se implementó una metodología cualitativa con un diseño flexible debido a la necesidad de obtener relatos espontáneos y propiciar la emergencia de significados desde la percepción de los participantes.

Al inicio de las entrevistas se manifestó a cada uno de los participantes que las mismas tendrán carácter confidencial para lo cual firmaron un consentimiento informado que garantice el anonimato de las respuestas y autorice al uso estrictamente académico de las mismas.

La muestra de tipo intencional estuvo compuesta por 40 adultos mayores, 28 mujeres de entre 65 y 86 años y 12 varones de entre 70 y 90 años, residentes en el área metropolitana de la Ciudad Autónoma de Buenos Aires, 
la elección de los sujetos se realizó mediante la técnica "bola de nieve", se entrevistaron en primer lugar a 3 personas conocidas por los investigadores y luego se pidió a estos sujetos que refieran personas por ellos conocidas para incorporar a la investigación, de esta manera se lograron las 40 entrevistas que fueron realizadas entre diciembre del año 2015 y octubre de año 2017, las entrevistas se llevaron a cabo en lugares sugeridos por los participantes.

Se estableció como criterio de inclusión o exclusión que los sujetos sean mayores de 60 años y que no evidencien fallas cognitivas en el curso de la entrevista.

El límite de 40 personas entrevistadas respondió a un criterio de saturación ya que los datos aportados por las nuevas entrevistas no modificaron las categorías, códigos y subcódigos analizados.

El equipo investigador elaboró un guión que incluía los siguientes ejes referidos a los cambios en el erotismo en el envejecimiento:

1. Cambios que se produjeron en el erotismo con el envejecimiento, para lo cual se estableció la definición de erotismo relativa a la amplitud de los goces y deseos, más allá de su correlato con la genitalidad.

2. Continuidades y discontinuidades en el erotismo a lo largo de la vida.

3. Incidencia de los prejuicios y estereotipos sobre la sexualidad en la vejez en la relación con su erotismo.

4. Prácticas, narrativas y registros sensoriales relacionados con el erotismo que se ponderan.

5. Estrategias que implementan para mantener el erotismo frente a los cambios ocurridos.

El registro de las entrevistas fue realizado mediante grabación de audio y desgrabación por un miembro del equipo.

El análisis de datos se realizó de manera manual y la confiabilidad se logró a través de comparaciones e integraciones constantes que permitieron posteriormente delimitar el material en categorías, códigos y subcódigos. Las categorías una vez construidas reflejaron un proceso de organización ético y émico ya que algunas de estas se correspondieron con categorías planteadas inicialmente y otras relativas a los significados que emergieron de los datos. 


\section{Iacub et al. - Desarticulando las fronteras del erotismo}

La duración de cada entrevista fue de entre 60 y 90 minutos, necesitando en algunos casos la realización de una re-entrevista ante situaciones que dificultan la expresión de las personas en un primer encuentro.

\section{Resultados}

Se describirán a continuación los resultados obtenidos en la investigación a partir del análisis de las categorías surgidas de los relatos de las personas entrevistadas.

\section{Las Características del Erotismo}

Esta categoría indica las diversas modalidades en que un sujeto describe sus expresiones y condicionamientos ante el deseo y el goce.

El primer código que lo especifica son "las expresiones del erotismo" donde se relatan los principales criterios que especifican esta etapa vital. Entre los subcódigos que lo especifican se encuentran:

El romanticismo entendido como la búsqueda de una relación que articule lo amoroso y lo sensual, y habilite otras formas de encuentro: "Yo tengo seguramente erotismo ahora también, pero es un erotismo romántico, un erotismo como aquellos amores que se transmitían a través de las cartas..." (Varón, 82 años).

El fantaseo como un proceso intelectual que excita y potencia al deseo: "A veces, ante la pasividad que tengo con mi marido, fantaseo con mi ex marido..." (Mujer, 68 años).

Los juegos de seducción como el conjunto de acciones tendientes a provocar la atracción erótica: "Hay un juego físico y erótico y de chistes, de chistes que rondan lo que tiene que ver con la sexualidad..." (Mujer, 76 años).

Las analogías con otras prácticas que producen resultados similares: "Lo más parecido al orgasmo que he experimentado es un final de concierto." (Mujer, 78 años).

Conclusiones del código expresiones del erotismo: aparecen particularmente abiertas, en parte porque muchas de las mujeres carecen de pareja y de encuentros sensuales habituales y por las carencias en el impulso 
sexual, lo que genera que se habiliten nuevas vías de producción de significados del erotismo.

El segundo código es "condiciones del erotismo" que indica aquellos criterios que se consideran necesarios para suscitar o limitar el erotismo. Se subdivide en diversos subcódigos.

La estimulación sensorial comprender los múltiples mecanismos para estimular el deseo y alcanzar el goce, entre los que se encuentran lo olfativo, lo visual y lo táctil. "Los olores son muy limitantes, por ejemplo el olor fuerte a orina me produce rechazo" (Varón, 74 años).

La cercanía fisica y temporal expresa la necesidad de besos, caricias y abrazos: "Yo tal vez esté con una persona y si no me abraza o no me besa no tengo deseo de estar con ella" (Mujer, 67 años). "La presentación" se asocia con los modos, actitudes y estilos resultan necesarios que se asociana la higiene, prolijidad, apariencia juvenil y valores intelectuales. "Una persona que no la veo que sea aseada, por ejemplo, que pasa en el tango mucho, no me interesa y por ahí nos contamos entre las mujeres." (Mujer, 69 años).

Conclusiones del código condiciones del erotismo: En este conjunto de condiciones aparecen tres criterios que denotan condiciones de diversa índole, un criterio más sensitivo, como el disgusto olfativo o la intensidad de contactos y sensaciones; otro más afectivo, y finalmente más estético asociado al cuidado personal.

\section{Los Cambios del Envejecimiento}

Esta categoría es definida como las transformaciones que se producen con el envejecimiento y que impactan sobre el erotismo a partir de cambios en el sujeto y en el otro.

El código "percepción del cuerpo envejecido" se define como el modo subjetivo de representar y concebir su cuerpo.

El subcódigo estética de la vejez: se refiere a la adecuación del cuerpo envejecido a las representaciones estéticas de una época.

Por momentos me miro al espejo y digo bueno, para los 73 todavía no estoy tan mal, me comparo con mi mamá que era muy gorda, no estoy tan gorda, tengo panza, las tetas se me fueron cayendo pero 


\section{Iacub et al. - Desarticulando las fronteras del erotismo}

por ahí un poco más arreglada... pero no, ya no estoy para que me digan algo. (Mujer, 73 años)

El subcódigo visibilidad de la vejez: implica los aspectos más o menos visibles de los cambios que introduce el envejecimiento.

...cuando vos sos adolescente no te importa nada, hoy es distinto, cuando sos adulto es más calmo...con la misma intensidad de cuando sos adolescente pero con los tiempos más lentos. Tenés la misma intensidad de cariño, solamente que somos más calmos, más tranquilos, más lentos, pero los sentimientos son los mismos. (Mujer, 79 años)

El subcódigo limitaciones de la edad refiere a la percepción de un cuerpo envejecido que impone -desde lo físico- restricciones para llevar a cabo determinadas prácticas sexuales.

...tenemos que tener en cuenta que por la edad nosotros tenemos incapacidad física para poder tener relaciones sexuales...las limitaciones están dadas porque la erección ya no existe...disminuye en una proporción muy importante. Es decir que será difícil tener relaciones sexuales. (...) Uno puede estar con una mujer, puede besarla, tocarla, hacer qué se yo, pero no puede tener un sexo con esa persona porque evidentemente, no tiene erección. (Varón, 90 años)

...Tener una relación sexual parados, no podemos. No podemos porque después está con el tema de la cintura, el tema de la cervical y yo también, pero ella más que yo. (...) una posición parados, trae incomodidades físicas. Entonces cuando hacemos el acto, que no es tan continuo, buscamos que dure y que sea más satisfactorio, entonces buscamos posiciones que no sean molestas, posiciones que no haya que hacer esfuerzo (Varón, 69 años)

La conclusión de la categoría cambios del envejecimiento: indica al envejecimiento como un cambio estético negativo en el sujeto y en los otros. Sin embargo, las lecturas que se realizan sobre el cuerpo no lo muestran 
como un todo homogéneo sino que se produce en partes, a las que se le atribuyen la condición de viejas, entre las que se encuentran las arrugas, la panza, el aumento de peso o la flacidez. Todos estos son considerados objetos que envejecen, dificultando e inhibiendo la convocatoria al deseo y el atractivo en el objeto. expresa de manera polar frente al cuerpo joven. Mientras que la juventud aparece asociada a la facilidad de convocar el deseo, a cuerpos torneados y delgados, la vejez conlleva la idea contraria. Así, estas polaridades se constituyen en mediadores estéticos de la erótica que habilitan o inhiben la aceptación del otro.

Los grados de aceptación ante los cambios varían según la magnitud de los mismos o su capacidad para ser disimulados. Asimismo aparecen algunas partes del cuerpo que no son vistas como envejecidas, y por ello son positivas, donde la persona siente que la representa, a diferencia de las envejecidas; $y$ negativas, que suponen una diferencia ante quien fue.

\section{Las Estrategias de Compensación}

Esta categoría describe los diversos mecanismos que se implementan en cada contexto para mantener el deseo y el goce, lo que implica al propio sujeto y su partenaire, ante las limitaciones y adversidades que se encuentran en ciertas formas de envejecer.

El sujeto puede transformar dichas vivencias en nuevas formas de selectividad vital, optimizando el bagaje de recursos particulares y donde los fallos se compensarían con mecanismos que reemplacen lo perdido. De este modo, la Selección, Optimización y Compensación, sintetizado como SOC (Baltes, 1997) es un modo de afrontar las dificultades y encontrar soluciones positivas.

Entre los subcódigos que los especifican se encuentran:

Selección: Se observa que mujeres y hombres encuentran en el arreglo personal (asistir a la peluquería, la compra y el uso de ropa y perfumes) una manera de continuar el erotismo a través de la seducción. Se propone una escena en donde los cambios introducidos funcionan como estimuladores del deseo y satisfacción de goce. 


\section{Iacub et al. - Desarticulando las fronteras del erotismo}

De todos modos, yo sé que uso buenos perfumes, eso es un sinónimo de seducción. Generalmente disfruto de vestirme bien, de oler bien. Yo me quiero más, por eso uso mejor ropa, mejores perfumes. (Varón, 74 años)

Optimización: Otro de los mecanismos implementados por los adultos mayores frente a aquellas limitaciones que impactan directamente en la genitalidad, es la posibilidad de habilitar prácticas que permitan focalizar y aumentar el tiempo de estimulación en otras zonas erógenas para mejorar el erotismo.

A lo largo de mi vida no le di importancia al clítoris y con M., dado que no había posibilidad de buenas penetraciones, empezamos a jugar más con el sexo oral y descubrí que después de una buena estimulación logré tener orgasmos con el clítoris.” (Mujer, 68 años)

Compensación: ante las dificultades que se presentan se buscan estrategias que eviten resultados indeseados o se encuentren goces alternativos.

Si yo estoy arriba de mi compañera ¿cómo puedo estimular su vulva? Me parece que con la posición del hombre de espaldas en la cama y la mujer arriba con su clítoris generando un masaje mutuo era mejor y yo buscaba esa posición. Ella lo podía disfrutar. Yo lo disfrutaba a medias porque muchas veces ya estaba en baja (sin erección). Pero se completó con el haber percibido que ella lo disfrutaba. Eso me compensó, sí... me sigue compensando. (Varón, 88 años)

Conclusiones de Estrategias del erotismo. Las personas seleccionan posiciones, espacios, modos que faciliten su encuentro, así como lo optimizan con prácticas y posiciones que mejoren el rendimiento y finalmente compensan ciertos límites con goces alternativos.

\section{Análisis Narrativos de los Resultados}

Las narraciones sobre el erotismo que se abordaron en esta investigación dieron cuenta de una variabilidad de situaciones que devela el potencial de 
deseo y goce que se presentan en esta etapa vital, aun cuando ciertos modos de abordar el erotismo puedan haberse modificado.

Los recorridos narrativos muestran estilos personales marcados por formas de representar la erótica, de interpretar los propios sentidos, como la mirada, lo táctil, lo olfativo o lo auditivo y dar espacio a los objetos que emergen como la boca, vagina, pene, mano, pies, pechos, espalda, pelo y mirada, para desde allí otorgarle sentidos prioritarios asociados con lo romántico, lo sensual, lo bello, lo necesario, entre otras referencias.

En la investigación emergen tres formas de relatar la experiencia del erotismo: lineal, eslabonada e inmanente y valorativa. El "relato lineal" describe un proceso en el cual resultan necesarias sensaciones físicas articuladas a objetos, estados emocionales y modos de realización personal y del partenaire, que cuentan con inicios, formas de desarrollo y finales, que pueden articularse de manera continua o no, y que resultan necesarios para la consecución del goce erótico.

Estos recorridos indican un alto nivel de control sobre el erotismo, ya que el relato previo parece imponerse sobre la escena misma.

Sí logro conectar a través de lo que son las caricias, los besos, el beso en el cuello, el roce en los pechos o estimularlo a él, en lo que sé que son sus zonas erógenas, me entrego al juego, pero mi sexualidad o mi disfrute mayor es muy genital. (Mujer 68 años)

El "relato eslabonado" describe una experiencia en la que las sensaciones se enlazan sin un orden previo, sino a partir de objetos que toman relevancia en el marco de la escena erótica. Lo que remite a un relato que apela a la inmanencia ya que las sensaciones son valoradas por situarse en la escena de goce. Los objetos toman una particular relevancia en la medida que se presentifican en un contexto que los encuadra, y de esa manera los define, sin requerir prioridades, ordenamientos ni objetos precisos, sino que cada uno de estos toma la cualidad del erotismo, en la medida que se combinen en dicho contexto. En este sentido, el relato sobre la cualidad de las sensaciones no puede explicarse totalmente ya que es el conjunto el que regula el valor de cada pieza.

En este caso los niveles de control parecen disminuir y la sorpresa frente al otro da cuenta de lo impredecible de una manera positiva. 
Ella estaba arriba mío y yo notaba cuando ella se reía como una loca, algo que nadie notó (se ríe), yo sentía cómo funcionaba ella por dentro cuando yo le hacía chistes y estaba arriba mío...es como que explota abajo (en la vagina) es como que te comprime y me gustaba porque es raro! ¡Me gustaba! (Varón, 77 años)

El relato valorativo describe un tránsito por cantidades de goces de diversa magnitud que le da valor a cada práctica sin que resulte necesario un orden de prioridad. En este caso el control sobre la situación aparece como algo que prima y define la carencia de sorpresas. "Tu pareja sabe las partes que a vos te gusta que te hagan. Acariciarte el pie por ejemplo, acariciarte la mano, besarte la oreja.” (Varón, 69 años)

\section{La Referencialización}

Las narrativas incluyen alusiones a objetos, sensaciones o discursos que pueden aparecer de maneras directas o indirectas, con mayores o menores cantidades de referencias o con más o menos usos de tropos del lenguaje. Hallamos dos modos de indicar estas diferencias a partir de variantes opuestas:

La localización vs la deslocalización. La localización implica referencias a objetos y situaciones muy específicos que incentivan y producen deseo y goce, mientras que lo deslocalizado alude a una multiplicidad de variantes que pueden emerger por sí mismas o por sus relaciones con otras.

No sé, soy bastante genital para el erotismo, nunca pude tener orgasmos de otra manera que no fuera con penetración o con sexo oral. (Mujer, 68 años)

No solamente es la penetración, el goce que se da es por un mimo, una caricia, un beso, es que te toque la mano, todo el placer que te da... (Mujer, 67 años)

\section{La Centralización Vs. la Fragmentación de los Escenarios}


En los relatos observamos formas de narrar el erotismo en base a menores o mayores cantidad de escenarios. Los escenarios condensan fantasías, goces, objetos articulados de maneras específicas que tienen la capacidad de convocar el deseo. En algunos pueden aparecer de maneras más cerradas y, en otros, más abiertas, con mayor posibilidad de concreción o de mantenerse en un plano mental.

¿Qué fantasías lo acompañaron a lo largo de su vida? A: siempre sexuales ¿no? Fantasías que se hicieron realidad después. La mayoría era con dos mujeres. (Varón, 74 años)

Siempre soy de fantasear, voy en el colectivo y veo un tipo que me gusta y entro a fantasear, como me pondría, como lo haría, qué haría, qué me pondría, que prepararía. E: ¿cómo lo harías el qué? C: las distintas posiciones. (Mujer, 71 años)

Las entrevistas muestran las dificultades que se imprimen en las formas del relato más lineales o con referencias más puntuales y con menor posibilidad de ampliar los escenarios para adecuarse a los cambios en el impulso sexual en las personas mayores.

Los obstáculos que se advierten aparecen en ciertos relatos de lo masculino, aunque no exclusivamente, que pareciera limitar los márgenes de comprensión de otros recursos, ya sea en la calificación de lo sensual, si no hubiera genitalidad, o en la posibilidad de disfrutar de maneras menos referencializadas y con mayor apertura al otro. Así también, ciertos discursos generacionales y de nivel educativo, también pueden condicionar la apertura o el cierre de referencias.

Sin embargo, aparecen condicionantes asociados a rasgos más personales o de relación de pareja que dieron cuenta de algunas oportunidades o cierres narrativos.

\section{Discusiones}

Se debe considerar que la muestra estuvo compuesta por un mayor número de mujeres y de clase social media y con educación secundaria $\mathrm{y}$ universitaria, por lo que en futuras investigaciones debería establecerse con 


\section{Iacub et al. - Desarticulando las fronteras del erotismo}

grupos poblacionales más amplios y diferencias por género, nivel educativo y clase social.

El haber focalizado en un grupo etario y preguntar retrospectivamente brinda un nivel de confianza en los cambios mostrados aunque sería valioso conocer si estos cambios fueron propios de esta etapa o se refieren a estilos personales, de género o generación. Por ello sería importante una investigación en diversos grupos de edades o de tipo longitudinal para conocer las trayectorias individuales a nivel del erotismo.

A partir de esta investigación surge el interés/ necesidad de cuantificar los resultados y comparar con otras franjas etéreas; partimos de una investigación en donde cada sujeto entrevistado comparó características del erotismo, dio cuenta de los cambios y de las estrategias pasadas y actuales en diferentes etapas de su vida mientras que en una futura investigación podría realizarse un estudio comparativo de la incidencia de los discursos de época, es decir, la erótica, sobre las valoraciones y la construcción de narrativas del erotismo.

\section{Conclusiones}

El erotismo en las personas mayores aparece como un mecanismo ineludible que pareciera articular el impulso sexual, la erótica de época y los modos singulares de construir significado a lo largo de las trayectorias personales. A su vez las expresiones del erotismo aparecen particularmente abiertas, lo que genera que se habiliten nuevas vías de producción de significados del erotismo. Mientras que los límites físicos aparecen expresados fuertemente en los accesos a la genitalidad.

En este sentido, las formas en que se traman los relatos permiten ver modos más apegados a esquemas rígidos y con un alto monto de control personal que dificultan manejar los límites corporales y los discursos hegemónicos tales como la potencia o lo juvenil .

Por otra parte es en los límites sociales, donde los códigos estéticos aparecen caracterizados como un cambio negativo. De este modo según varíen los grados de aceptación ante los cambios se podrá observar de qué manera el sujeto es capaz de transformar su deseo y goce en formas alternativas, expresando formas ya conocidas o elaborando nuevas; 
posibilitando reemplazos que pueden compensar lo perdido y redescubrir recursos que no habían tenido el mismo valor.

Entendemos que la selección de estrategias que se halló en el relato de los entrevistados no se trata de innovaciones, por el contrario son recursos recuperados de experiencias previas y ampliadas al objetivo actual: mantener el erotismo y evitar resultados indeseados asociados al envejecimiento, apareciendo relatos que eslabonan las vivencias de maneras más ricas en relación a una vivencia menos pautada, y que posibilitan, cuando sea necesario, la compensación o reemplazo de las pérdidas ocurridas.

\section{Referencias}

Baltes, P. B. (1997). On the Incomplete Architecture of Human Ontogeny:

Selection, Optimization, and Compensation as a Foundation of

Developmental Theory. American Psychologist, 52(4), 366-380. doi: 10.1037//0003-066x.52.4.366

Bauman Z. (1999). On postmodern uses of sex. En M. Featherstone, (Comp.), Love and Eroticism (19-33). Londres: Sage Publications. Bellato Gil, L. (2016). Traigo el deseo a flor de piel. Espacio, corporalidad y experiencia erótica en un grupo de personas mayores de sectores medios en Tuxtla Gutiérrez. Chiapas, San Cristóbal de Las Casas: CESMECA-UNICACH. Recuperado de https://rua.ua.es/dspace/bitstream/10045/52905/1/tesis_bellato_gil.p df

Bortz, W. M., Wallace, D. H., y Wiley, D. (1999). Sexual function in 1,202 aging males: differentiating aspects, The Journals of Gerontology. Series A, Biological Sciences and Medical Sciences, 54(5), 237-241. doi: 10.1093/gerona/54.5.m237

Calasanti, T.M. y Slevin, K.F. (2001). Gender, Social Inequalities and Aging. California: Altamira Press.

Derrida, J. (1988). Limited Inc. Evanston: North Western University Press. Featherstone, M. y Hepworth, M. (1998). Aging and old age: reflections on the postmodern life course, en B. Bytheway, T. Keil, P. Allat y A. Bryman (eds.). Becoming and Being Old: Sociological Approaches to Later Life. Londres: Sage, 143-157. 
Fileborn, B., Thorpea, R., Hawkesb, G., Minichielloa, V., Pittsa, M., y Dunec, T. (2015). Sex, desire and pleasure: considering the experiences of older Australian women. Sexual and Relationship Therapy, 30(1), 117-130. doi: 10.1080/14681994.2014.936722

Foucault, M. (1995). Historia de la Sexualidad. La voluntad de saber. Buenos Aires: Siglo XXI.

Freud, S. (1915). Pulsiones y destinos de pulsión. En Amorrortu (Eds.), Sigmund Freud. Obras completas. Vol. XIV, 105-106.

Freud, S. (1905). Tres ensayos de teoría sexual, en Amorrortu (Eds.), Sigmund Freud. Obras completas. Vol. VII, 109-232.

Huick, M. (1977). Sex and the older woman, en L. Troll, J. Israel y K. Israel (eds.), Looking Ahead: A Woman's Guide to the Problems and Joys of Growing Older. Englewook Cliffs, N. J.: Prentice Hall.

Iacub, R. (2003). La Post- Gerontología. La Política de las Edades. Revista de Trabajo Social, Perspectivas Notas sobre Intervención y Acción Social, 8(12), 31-40.

Iacub, R. (2002). La Postgerontología: hacia un renovado estudio de la gerontología. Revista Latinoamericana de Psicología, 34(1-2) 155157. Recuperado de https://www.redalyc.org/pdf/805/80534212.pdf Iacub, R (2013). Nuevas reflexiones sobre la Posgerontología. Revista Kairós Gerontologia,16(4), 295-311. Recuperado de https://revistas.pucsp.br/index.php/kairos/article/viewFile/19729/146 10

Iacub, R. (2005). Reflexión acerca de los transetarios. Una proyección social posmoderna. Revista Psico Logos, 23-31.

Iacub, R. (2006). Erótica y Vejez. Perspectivas de Occidente. Buenos Aires: Paidós.

Iacub, R. (2015). La sabiduría del erotismo en la vejez. Revista Kairós Gerontologia, 18(20), 87-102. Recuperado de https://revistas.pucsp.br/kairos/article/viewFile/29193/20399

Lindau, S., Schumm, P., Lauman, E., Levinson, W., O’Muircheartaigh, C., y Waite, L. (2007). A Study of Sexuality and Health among Older Adults in the United States. The New England Journal of Medicine, 357(8), 762-774. doi: 10.1056/NEJMoa067423 
López Sánchez, F. (2005). Experiencia amorosa en la vejez. Revista Española de Geriatría y Gerontología, 40(3), 135-137. doi: 10.1016/S0211-139X(05)74844-7

Masters, W. y Johnson, V. (1966). Human Sexual Response. Boston: Brown and Company.

Organización Mundial de la Salud (2006). 'Defining sexual health: report of a technical consultation on sexual health, 28-31 enero 2002, Ginebra.

Paz, O. (2004). La llama doble. México: Seix Byarral.

Sandberg, L. (2011). Getting Intimate: a feminist analysis of old age, masculinity \& sexuality. Linköping: LiU-Tryck.

Siever, M.D. (1994). Sexual orientation and gender as factors in socioculturally acquired vulnerability to body dissatisfaction and eating disorders. Journal of Consulting and Clinical Psychology, 62(2), 252-260. doi: 10.1037/0022-006X.62.2.252

Smith, L.J., Mulhall, J.P., Deveci, S., Monaghan, N. y Reid, M.C. (2007). Sex after seventy: a pilot study of sexual function in older persons. Recuperado de https://www.ncbi.nlm.nih.gov/pubmed/17727349

Starr, B. D. y Weiner, M. B. (1981). On sex and sexuality in the mature years. New York: Stein and Day. 
24 Iacub et al. - Desarticulando las fronteras del erotismo

Ricardo Iacub, profesor titular en la Universidad Nacional de Buenos Aires y Doctor en Psicología

Patricia Hidalgo López, Licenciada en Psicología y Sexóloga Clínica

Martín Osvaldo Winzeler, Licenciado en Psicología

Valeria Bourlot, Licenciada en Psicología

Mariana Laura Gil de Muro, Licenciada en Psicología

Mariana Paz, Licenciada en Psicología

Mónica Liliana Bellas, Licenciada en Psicología

Luciana Machluk, Licenciada en Psicología

Rocío Vazquez Jofré, Licenciada en Psicología

Patricia Boggiano Licenciada en Psicología

Dirección de contacto: ricardoiacub@gmail.com 